\title{
PTX3 Intercepts Vascular Inflammation in Systemic Immune-Mediated Diseases
}

\begin{abstract}
Giuseppe A. Ramirez ${ }^{1,2,3}$, Patrizia Rovere-Querini ${ }^{1,3}$, Miriam Blasi ${ }^{1,3}$, Silvia Sartorelli ${ }^{1}$, Maria Chiara Di Chio ${ }^{1}$, Mattia Baldini 1,3, Rebecca De Lorenzo 1,3, Enrica P. Bozzolo ${ }^{2}$, Roberto Leone ${ }^{4}$, Alberto Mantovani ${ }^{4,5,6}$, Angelo A. Manfredi ${ }^{1,2,3 *}$ and Enrico Tombetti ${ }^{1,2,3}$

${ }^{1}$ Università Vita-Salute San Raffaele, Milan, Italy, ${ }^{2}$ Unit of Immunology, Rheumatology, Allergy and Rare Diseases, IRCCS Ospedale San Raffaele, Milan, Italy, ${ }^{3}$ Division of Immunology, Transplantation and Infectious Immunity, IRCCS Ospedale San Raffaele, Milan, Italy, ${ }^{4}$ Humanitas Research Center - IRCCS, Rozzano, Italy, ${ }^{5}$ Humanitas University, Rozzano, Italy, ${ }^{6}$ The William Harvey Research Institute, Queen Mary University of London, London, United Kingdom
\end{abstract}

PTX3 is a prototypic soluble pattern recognition receptor, expressed at sites of inflammation and involved in regulation of the tissue homeostasis. PTX3 systemic levels increase in many (but not all) immune-mediated inflammatory conditions. Research on PTX3 as a biomarker has so far focused on single diseases. Here, we performed a multi-group comparative study with the aim of identifying clinical and pathophysiological phenotypes associated with PTX3 release. PTX3 concentration was measured by ELISA in the plasma of 366 subjects, including 96 patients with giant cell arteritis (GCA), 42 with Takayasu's arteritis (TA), 10 with polymyalgia rheumatica (PMR), 63 with ANCA-associated systemic small vessel vasculitides (AAV), 55 with systemic lupus erythematosus (SLE), 21 with rheumatoid arthritis (RA) and 79 healthy controls $(H C)$. Patients with SLE, AAV, TA and GCA, but not patients with RA and PMR, had higher PTX3 levels than HC. PTX3 concentration correlated with disease activity, acute phase reactants and prednisone dose. It was higher in females, in patients with recent-onset disease and in those with previous or current active vasculitis at univariate analysis. Active small- or large- vessel vasculitis were the main independent variables influencing PTX3 levels at multivariate analysis. High levels of PTX3 in the blood can contribute to identify an increased risk of vascular involvement in patients with systemic immune-mediated diseases.

Keywords: PTX3, autoimmunity, lupus, rheumatoid arthritis, Takayasu arteritis, giant cell arteritis, ANCA associated small vessel vasculitis, intravascular immunity

\section{INTRODUCTION}

GA, Rovere-Querini Blasi M, Sartorelli S, Di Chio MC, Baldini M, De Lorenzo R, Bozzolo EP

Leone R, Mantovani A, Manfredi AA and Tombetti E (2019) PTX3 Intercepts Vascular Inflammation in Systemic Immune-Mediated Diseases.

Front. Immunol. 10:1135

doi: 10.3389/fimmu.2019.01135
Vascular inflammation reflects the dynamic interaction of circulating cells, blood molecules and vascular structures which plays a role in vascular homeostasis and in systemic or tissue/organlimited autoimmunity (1-5). The vasculature recruits cellular and immune effectors to facilitate the intercellular signaling required to deploy an inflammatory and immune response $(5,6)$. Vessels are frequently targeted in immune mediated-diseases, although in a subset of patients vascular inflammation is prominent, resulting in overt vasculitis. 
Pentraxins are part of an ancestral humoral innate network, evolutionarily rooted before the divergence of the immune and the haemolymphatic system. Pentraxin-3 (PTX3), a member of the long-pentraxin family, has changed little during the evolution, likely due to its role in multiple biological events $(7,8)$. In contrast to other pentraxins such as C-reactive protein (CRP), PTX3 is mostly generated at sites of inflammation rather than as a consequence of centralized hepatic synthesis. Neutrophils massively release PTX3 upon activation, while endothelial cells or macrophages synthetize the molecule, sustaining PTX3 production for longer times (9-11). In the extracellular space, PTX3 opsonizes self and foreign antigens and contributes to the structural and functional fitness of the extracellular matrix. Evidence has been acquired for a potential pathogenic role of PTX3 in a broad range of events from host defense to fertility, cancer biology, autoimmunity, regulation of angiogenesis and tissue repair $(7,12-19)$.

Enhanced expression of PTX3 has been reported in multiple systemic autoimmune diseases (20-27). Given that most cellular sources of PTX3 can be involved in vascular inflammation, and that PTX3 has been shown to be specifically involved in the regulation of the cross talk between the main players of intravascular immunity, including neutrophils, apoptotic cells, platelets, endothelial and antigen presenting cells $(22,28,29)$, we undertook an observational study assessing systemic expression of PTX3 in healthy subjects and multiple inflammatory diseases with variable vascular involvement.

\section{PATIENTS AND METHODS}

Upon written informed consent, 366 subjects followed up at San Raffaele University Hospital, Milan, Italy were recruited including: 96 patients with GCA, 42 with TA, 10 with PMR, 38 with granulomatosis with polyangiitis (GPA), 15 with eosinophilic granulomatosis with polyangiitis (EGPA), 10 with microscopic polyangiitis (MPA), 55 with systemic lupus erythematosus (SLE), and 21 with rheumatoid arthritis (RA). Seventy-nine healthy volunteers served as controls. All patients gave their written informed consent for participation in this study (Autoimmuno-Mol protocol, approved by the Ethics Committee of the San Raffaele Institute, Milan, Italy; reference number 2/2013/INT). Patients were classified according to the 1990 American College of Rheumatology (ACR) classification criteria for GCA and PMR (30), the 1996 Sharma's diagnostic criteria for TA (31), the European Medicine Agency algorithm

\footnotetext{
Abbreviations: AAV, ANCA-associated vasculitis; ACR, American College of Rheumatology; ANCA, anti-neutrophil cytoplasmic antibodies; BILAG, British Isles Lupus Assessment Group; BVAS, Birmingham Vasculitis Activity Score; CRP, C-reactive protein; DAS-28, 28-joint disease activity score EGPA, eosinophilic granulomatosis with polyangiitis; ESR, erythrocyte sedimentation rate; GPA, granulomatosis with polyangiitis; HC, healthy controls; ITAS, Indian Takayasu Activity Score; MPA, microscopic polyangiitis; PDN, prednisone; PGA, Physician's global assessment scale; PMR, polymyalgia rheumatica; PTX3, pentraxin-3; RA, rheumatoid arthritis; SDI, SLICC/ACR damage index; SLE, systemic lupus erythematosus; SLEDAI, SLE disease activity index; SLICC, SLE international collaborating clinics; TA, Takayasu's arteritis; TADS, TA Damage Score; VAS, visual analog scale; VDI, vasculitis damage index.
}

for classification of GPA, EGPA and MPA (32), the revised 1997 ACR or the 2012 SLE International Collaborating Clinics (SLICC) classification criteria for $\operatorname{SLE}(33,34)$ and the 2010 ACR/European League Against Rheumatism(EULAR) classification criteria for RA (35).

Basic demographics (including gender, age at sampling and disease duration), disease activity and accrued irreversible damage, dose of prednisone or equivalents, erythrocyte sedimentation rate (ESR) and CRP values at time of sampling were recorded. In patients with SLE, complement levels and anti-DNA titres were collected. Disease activity for group comparison was quantitated by employing a 28-joint disease activity score (DAS-28) for RA, the SLE disease activity index 2000 version (SLEDAI-2K) for SLE (36), the Birmingham Vasculitis Activity Score version 3 (BVAS v3) for anti-neutrophil cytoplasm antibody (ANCA)-associated vasculitides (AAV) (37) and the Indian Takayasu Activity Score for TA (ITAS2010) (38). In patients with SLE, disease activity was also estimated by employing the British Isles Lupus Assessment Group (BILAG) 2004 version index (39) and a 0.0-3.0 physician global assessment scale (PGA). A 0-10 visual analog scale (VAS) also measured SLE patients' impression about their global health status. Organ damage was determined by the SLICC/ACR Damage Index (SDI) for SLE (40), the Vasculitis Damage Index (VDI) for AAV and GCA (41) and the TA Damage Score (TADS) for TA (42). Disease activity and damage scores were made homogeneous by calculating Z-scores (i.e., $\frac{x-\text { mean }}{\text { standard deviation }}$ ) for activity and damage (Z-activity and $\mathrm{Z}$-damage). In parallel to quantitative assessment, a binary evaluation of disease activity and damage was performed. The former was based on the Physician Global Assessment of disease avidity (Inactive vs. Active/smoldering), the latter by the presence vs. absence of items related to vasculitic manifestations in the abovementioned scores. In patients with SLE, lupus chilblains, skin/digital vasculitis/ischemia, urticarial vasculitis, gastrointestinal vasculitis, choroidopathy or retinal vasculitis, cerebral vasculitis and alveolar hemorrhage were considered as relevant vasculitic manifestation, whereas Raynaud's phenomenon was not. In patients with AAV, "pure" vasculitic manifestations included absence of ear-nose-throat (ENT) or orbital involvement and presence of purpura, scleritis, episcleritis, optic neuritis, renal involvement, peripheral neuropathy, hemorrhagic alveolitis, or diagnosis of MPA.

PTX3 plasma levels were measured by a sandwich ELISA based on original reagents developed in house. 96 well plates (Nunc MaxiSorp cat. 446612) were coated with $100 \mu \mathrm{l}$ antihPTX3 monoclonal antibody (MNB4 (43) $1 \mu \mathrm{g} / \mathrm{ml}-100 \mathrm{ng} /$ well) in coating buffer $(15 \mathrm{mM}$ carbonate buffer $\mathrm{pH} 9.6)$ and incubated overnight at $4^{\circ} \mathrm{C}$. Plates were washed after each step with $300 \mu \mathrm{l} /$ well of washing buffer (PBS 1X with $\mathrm{Ca}^{++} \mathrm{Mg}^{++}+$ $0.05 \%$ Tween 20, pH 7.00). After coating, non-specific binding to the plates was blocked with $5 \%$ dry milk in washing buffer ( $2 \mathrm{~h}$ at room temperature), then $50 \mu \mathrm{l}$ in duplicate of recombinant human PTX3 standard (from $75 \mathrm{pg} / \mathrm{ml}$ to $2.4 \mathrm{ng} / \mathrm{ml}$ ) and human plasma (diluted in PBS $1 \mathrm{X} \mathrm{w/O} \mathrm{Ca}^{++}$ $\mathrm{Mg}^{++}+2 \%$ BSA, $\mathrm{pH} 7.00$ ), were plated. $1 \mu \mathrm{l}$ of $2.5 \%$ Polybrene was added to $50 \mu \mathrm{l}$ of plasma and incubated at room temperature for $10 \mathrm{~min}$ before dilution. After $2 \mathrm{~h}$ at 
TABLE 1 | General features of patients included in the study.

\begin{tabular}{|c|c|c|c|c|c|c|}
\hline & $\mathrm{RA}(n=21)$ & SLE $(n=55)$ & $\begin{array}{c}\text { PMR }(n= \\
10)\end{array}$ & $\operatorname{AAV}(n=63)$ & GCA $(n=96)$ & TA $(n=42)$ \\
\hline Age at diagnosis (year) & ND & $\begin{array}{c}26.2 \\
(18.6-34.2)\end{array}$ & $\begin{array}{c}72.0 \\
(68.5-73)\end{array}$ & $\begin{array}{c}48.5 \\
(36.5-61.5)\end{array}$ & $\begin{array}{c}74.0 \\
(67.0-77.0)\end{array}$ & $\begin{array}{c}30.0 \\
(24.0-40.5)\end{array}$ \\
\hline Age at sampling (years) & $\begin{array}{c}63.0 \\
(43.0-67.0)\end{array}$ & $\begin{array}{c}38.2 \\
(31.2-48.9)\end{array}$ & $\begin{array}{c}73.0 \\
(69.3-77)\end{array}$ & $\begin{array}{c}59.5 \\
(47.8-67.9)\end{array}$ & $\begin{array}{c}75.2 \\
(69.4-79.5)\end{array}$ & $\begin{array}{c}46.0 \\
(35-53)\end{array}$ \\
\hline $\mathrm{ESR}(\mathrm{mm} / \mathrm{h})$ & $\begin{array}{c}16.5 \\
(12.8-23.5)\end{array}$ & $\begin{array}{c}20.0 \\
(7.0-38.5)\end{array}$ & $\begin{array}{c}30.0 \\
(20.0-50.0)\end{array}$ & $\begin{array}{c}13.0 \\
(6.5-31.5)\end{array}$ & $\begin{array}{c}31.0 \\
(18.0-57.8)\end{array}$ & $\begin{array}{c}15 \\
(7.8-30.3)\end{array}$ \\
\hline CRP (mg/l) & $\begin{array}{c}3.5 \\
(2-6.7)\end{array}$ & $\begin{array}{c}2.1 \\
(0.3-6.1)\end{array}$ & $\begin{array}{c}10.4 \\
(8.7-22.3)\end{array}$ & $\begin{array}{c}0.8 \\
(0.23-6.2)\end{array}$ & $\begin{array}{c}11.0 \\
(2.26-31.4)\end{array}$ & $\begin{array}{c}2.25 \\
(1.03-7.3)\end{array}$ \\
\hline PDN dose at sampling (mg/day) & $\begin{array}{c}5.0 \\
(2.5-5)\end{array}$ & $\begin{array}{c}3.8 \\
(0.0-5.0)\end{array}$ & $\begin{array}{c}1.9 \\
(0.0-17.2)\end{array}$ & $\begin{array}{c}5.0 \\
(5.0-6.5)\end{array}$ & $\begin{array}{c}5.0 \\
(0.0-12.5)\end{array}$ & $\begin{array}{c}5.0 \\
(0.0-5.0)\end{array}$ \\
\hline Z-activity & $\begin{array}{c}-0.42 \\
(-0.47--0.28)\end{array}$ & $\begin{array}{c}-0.33 \\
(-0.56-0.35)\end{array}$ & NA & $\begin{array}{c}-0.4 \\
(-0.4--0.07)\end{array}$ & $\begin{array}{c}-0.23 \\
(-0.23--0.07)\end{array}$ & $\begin{array}{c}-0.42 \\
(-0.47--0.28)\end{array}$ \\
\hline Z-damage & ND & $\begin{array}{c}-0.2 \\
(-0.2--0.07)\end{array}$ & NA & $\begin{array}{c}-0.06 \\
(-0.06-0.01)\end{array}$ & $\begin{array}{c}-0.14 \\
(-0.14--0.06)\end{array}$ & $\begin{array}{c}-0.12 \\
(-0.57-0.19)\end{array}$ \\
\hline
\end{tabular}

$37^{\circ} \mathrm{C}$, plates were incubated with $100 \mu \mathrm{l} /$ well of purified and biotinylated rabbit IgG anti hPTX3 (5 ng/well) in washing buffer ( $1 \mathrm{~h}$ at room temperature), followed by incubation with $100 \mu \mathrm{l} /$ well-streptavidin conjugated to horseradish peroxidase (cat. SB01-61, Biospa, Milan, Italy) diluted 1:2,000 in washing buffer ( $1 \mathrm{~h}$ at room temperature). Finally, $100 \mu \mathrm{l}$ of 1 -Step ${ }^{\mathrm{TM}}$ Ultra TMB-ELISA Substrate Solution (cat. 34029, Thermo Scientific, Rockford, IL, USA) were added and the reaction was blocked after $10 \mathrm{~min}$ with $50 \mu \mathrm{l}$ of $2 \mathrm{M}$ Sulphuric Acid $\left(\mathrm{H}_{2} \mathrm{SO}_{4}\right)$ before reading the plates at $450 \mathrm{~nm}$ in an automatic ELISA reader. All the procedure was performed by personnel blind to patients' characteristics. For each biological sample, 2 dilutions in duplicate wells were evaluated and mean PTX3 content was calculated converting Abs450 values to protein concentration by means of the standard curve with recombinant purified hPTX3. Analysis was performed with SoftMax Pro software v5.3 (MDS Analytical Technologies, USA) and linear regression was used to interpolate unknown samples. Lower limit of detection of the assay was $75 \mathrm{pg} / \mathrm{ml}$, interassay variability was from 8 to $10 \%$; no cross reaction was observed with short pentraxins CRP and SAP.

PTX3 was measured in four different batches. Inter-batch variability was corrected by normalization based on $\mathrm{HC}$ samples. The relative frequencies of laboratory and clinical categorical variables were compared by using chi-square test with Fisher's exact correction as appropriate. Quantitative variables were compared by using Spearman's correlation tests. Differences in quantitative variables among groups were assessed by employing Mann-Whitney U-test or KruskalWallis' test for multiple comparisons. We also employed generalized linear models with gamma distribution of the dependent variables and log function as a link function to assess the effect of each quantitative or qualitative variable on PTX3 levels. Data were processed and analyzed by employing Microsoft Excel ${ }^{\circledR} 2013$ and IBM SPSS ${ }^{\circledR}$ version 15-23. Data are expressed as median (interquartile range, IQR) unless otherwise specified.

\section{RESULTS}

\section{Expression of PTX3 in Systemic Autoimmune Diseases}

We enrolled 287 patients diagnosed with systemic autoimmune diseases. Seventy-nine volunteers served as controls. Twentyone patients had RA, a systemic inflammatory disease targeting the synovial membrane, 55 had SLE, the prototypic systemic autoimmune disease, including 19 patients with vasculitic features, ten had PMR, a fruste form of GCA with prominent osteoarticular inflammation sparing the vasculature. Moreover, we enrolled patients with primary systemic vasculitis of small vessels ( $n=63$, including 38 with GPA, 15 with EGPA) and large vessels ( $n=138$, including 96 with GCA and 42 with TA). Table 1 summarizes patients' main characteristics.

PTX3 levels were significantly higher in patients with systemic inflammatory immune-mediated and autoimmune diseases $(2.33 \mathrm{ng} / \mathrm{ml}$, IQR: $1.26-4.89, n=287)$ than in HCs $(1.22 \mathrm{ng} / \mathrm{ml}$, IQR:0.80-1.98, $n=79 ; p<0.001$ ). However, despite often comparable levels of systemic inflammation, PTX3 expression was heterogeneous in patients with different diseases. RA and PMR had plasma PTX3 levels comparable to those of HC. In contrast, PTX3 plasma levels of patients with SLE, AAV, GCA, and TA were significantly higher. Moreover, patients with SLE had higher levels of PTX3 compared to patients with AAV, GCA and TA ( $p<0.001$ for AAV and TA, $p=0.001$ for GCA; Figure 1).

\section{PTX3 Correlates With Disease Activity but Not With Accrued Damage}

On univariate analysis in the general group of subjects who had been studied, PTX3 levels were higher in females than in males (Figure 2A) and did not correlate with disease duration (Table 2). Patients with recent onset disease (i.e., up to 6 months) had higher PTX3 levels compared to patients with longer disease duration (Figure 2B). PTX3 levels positively correlated with Zactivity (Rho $=0.181, p=0.016, n=176$ Figure $3 \mathrm{~A}$ ), with acute phase reactants $(\mathrm{ESR}$ and $\mathrm{CRP}, \mathrm{Rho}=0.229$ and $\mathrm{Rho}=0.128, p$ 


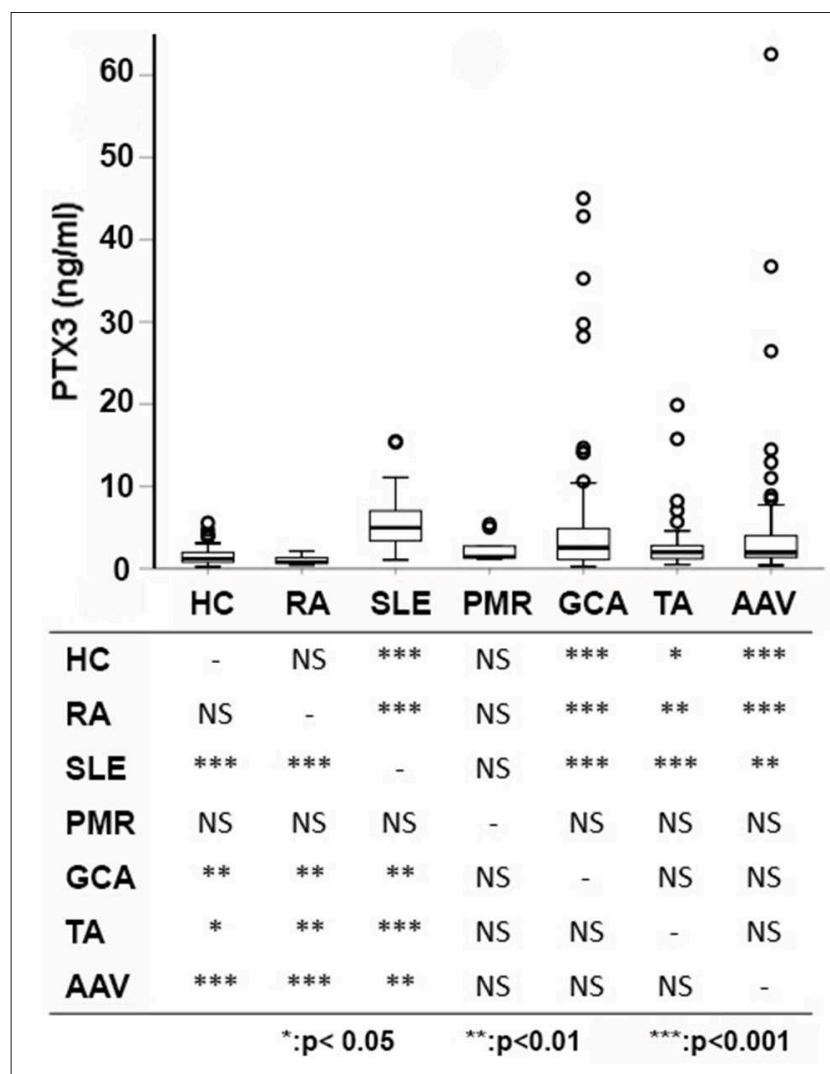

FIGURE 1 | PTX3 levels among different diseases. PTX3 plasma levels were compared among patients with multiple distinct autoimmune diseases and $\mathrm{HC}$. Pairwise comparisons among groups are reported below. Patients with PMR and RA did not differ from $\mathrm{HC}$, whereas patients with other immune-mediated diseases showed significantly higher levels of PTX3 compared to patients with RA and HC. Patients with SLE had higher levels of PTX3 compared to patients with large- (TA, GCA) and small-vessel vasculitides (AAV). AAV, ANCA-associated vasculitides; GCA, giant cell arteritis; $\mathrm{HC}$, healthy controls; PMR, polymyalgia rheumatica; RA, rheumatoid arthritis; SLE, systemic lupus erythematosus; TA, Takayasu's arteritis; ${ }^{*} p<0.05$; ${ }^{\star *} p<0.01$; ${ }^{\star \star *} p<0.001$.

$<0.001$ and $p=0.035, n=261$ and $n=269$, respectively) and with steroid dose (Rho $=0.198, p=0.001, n=259$; Table 1 and Figure 3B). On the contrary, PTX3 levels did not correlate with $\mathrm{Z}$-damage $(\mathrm{Rho}=-0.006, p=0.930)$. PTX3 levels were higher in patients with active disease as compared to those with quiescent disease (3.28, IQR $1.27-7.21, n=123$ vs. 1.74 , IQR: $1.07-3.16$, $n=222$ ), while similar levels were observed in patients with or without organ damage. Accordingly, PTX3 levels were higher in patients with active disease and on corticosteroid treatment, but did not differ between patients with or without chronic damage (Figures 4A-C).

\section{PTX3 Reflects Vascular Inflammation}

Subjects with previous vasculitic manifestations had higher PTX3 levels than those without $(2.3 \mathrm{ng} / \mathrm{ml}, \mathrm{IQR}=1.26-4.83, n=$ 220 vs. $1.43 \mathrm{ng} / \mathrm{ml}, \mathrm{IQR}=0.88-2.81, n=146 ; p<0.001)$ and patients with active vasculitis had higher levels of PTX3 compared to patients without evidence of vasculitis at time of sampling $(3.15 \mathrm{ng} / \mathrm{ml}, \mathrm{IQR}=1.31-7.75, n=85 \mathrm{vs} .1 .72 \mathrm{ng} / \mathrm{ml}$,
IQR $=1.08-3.37, n=278 ; p<0.001$ Figure 4D). PTX3 plasma levels were higher either in patients with a history of smallvessel inflammation $(3.21 \mathrm{ng} / \mathrm{ml}, \mathrm{IQR}=1.57-6.58, n=70)$ or large vessel inflammation $(2.27 \mathrm{ng} / \mathrm{ml}, \mathrm{IQR} 1.12-4.29, n=$ 138) as compared to those without history of vasculitic features $(1.43 \mathrm{ng} / \mathrm{ml}, \mathrm{IQR}=0.88-2.81, n=157 ; p<0.001$ and $p$ $=0.003$, respectively, Figure 4E). Moreover, active small-vessel inflammation $(4.10 \mathrm{ng} / \mathrm{ml}, \mathrm{IQR}=2.16-8.09, n=21)$ or active large-vessel inflammation $(2.49 \mathrm{ng} / \mathrm{ml}, \mathrm{IQR}=1.10-7.95, n=64)$ identified two subsets of patients with higher PTX3 plasma levels than patients without active vascular inflammation $(1.72 \mathrm{ng} / \mathrm{ml}$, $\mathrm{IQR}=1.09-3.39, n=281 ; p<0.001$ for both tests, Figure 4F).

\section{PTX3 and Disease-Specific Clinical Features}

Both in SLE and AAV, pure vasculitic manifestations are not detectable in all cases. Analysis of the patients with AAV revealed a positive correlation of PTX3 and CRP levels (rho $=0.362 ; p$ $=0.005, n=58$ ), ESR (rho $=0.272 ; p=0.037, n=59$ ) and ANCA titres at blood sampling (rho $=0.266 ; \mathrm{p}=0.049, n=$ 55). PTX3 also correlated with disease activity as measured by BVAS in patients with GPA and MPA (rho $=0.362 ; p=0.014$, $n=46)$. PTX3 levels were higher in patients with exclusive vasculitic manifestations $(3.51 \mathrm{ng} / \mathrm{ml}, \mathrm{IQR}=2.00-7.92, n=16$ vs. $1.83 \mathrm{ng} / \mathrm{ml}, \mathrm{IQR}=1.28-2.97$ in patients with concomitant granulomatous lesions, $n=47 ; p=0.011$ ) and lower in patients with ear-nose-throat involvement $(1.84 \mathrm{ng} / \mathrm{ml}, \mathrm{IQR}=1.32-2.97$, $n=43$ vs. $3.37 \mathrm{ng} / \mathrm{ml}, \mathrm{IQR}=1.74-7.92, n=20 ; p=0.039)$.

PTX3 levels of patients with SLE correlated with disease activity as assessed by SLEDAI- $2 \mathrm{~K}$ in the whole group of patients (rho $=0.361 ; p=0.007, n=55$ ) and in those who were off corticosteroids ( $p<0.001, n=19$; Table 3), but not in patients receiving prednisone. In the latter patients, a positive correlation was observed between PTX3 levels and prednisone dose (rho = $0.198 ; p=0.001, n=36$ ). Patients with $>1$ moderately-to-highly active (A, B) BILAG domain had significantly higher PTX3 levels than those with more limited disease activity extent $(7.23 \mathrm{ng} / \mathrm{ml}$, $\mathrm{IQR}=5.51-9.58, n=9$ vs. $4.29 \mathrm{ng} / \mathrm{ml} . \mathrm{IQR}=3.09-6.34, n=$ $46 ; p=0.041$ ). PTX3 also directly correlated with PGA (rho = 0.383; $p=0.004, n=55)$ and inversely with patient-reported VAS ( rho $=-0.331 ; p=0.013, n=55$ ) and C4 levels (rho $=$ $-0.458 ; p=0.001, n=51)$. There was no significant correlation with age, disease duration or with CRP concentration or antiDNA antibodies titres (Table 3). CRP was higher in patients with $>1 \mathrm{~A} / \mathrm{B}$ BILAG domain $(p=0.004)$, but its concentration did not correlate with SLEDAI-2K or prednisone dose. SLE patients with active disease tended to have higher levels of PTX3 compared to patients with inactive disease. This trend was more evident in patients with past or current evidence of vascular inflammation (Supplementary Figure 1).

\section{PTX3 Levels Reflect Small- and Large-Vessel Inflammation at Multivariate Analysis}

We performed two multivariate linear regressions of PTX3 plasma levels with a stepwise backward approach. The first 

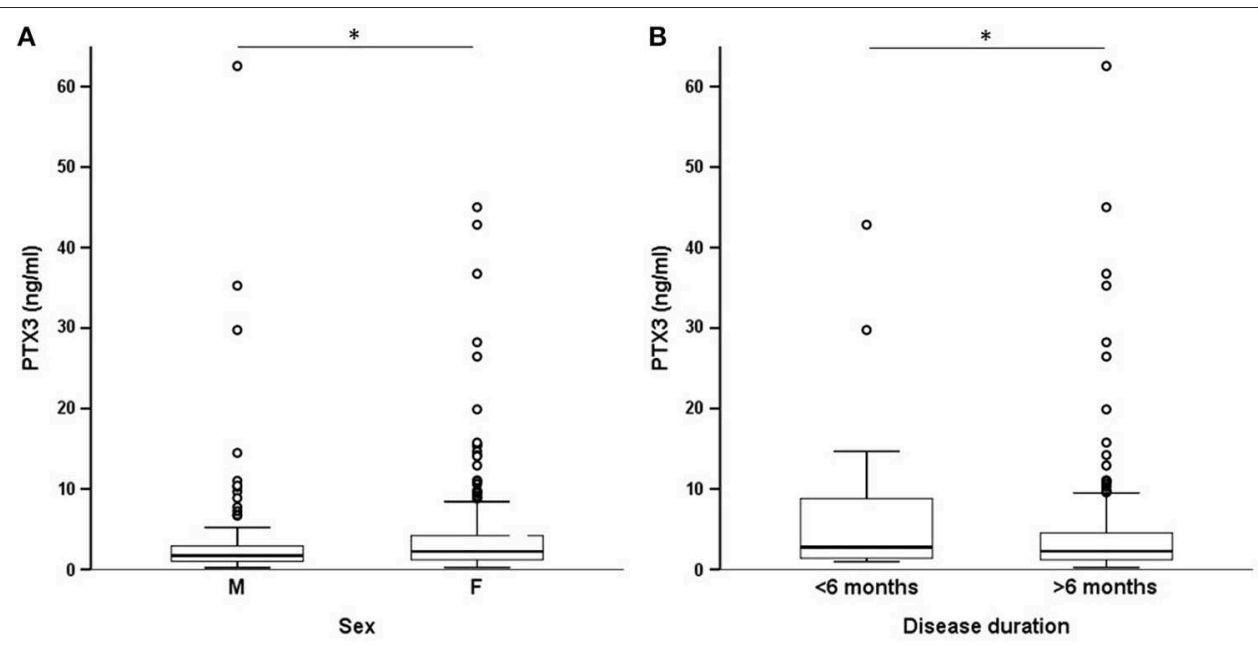

FIGURE 2 | PTX3 levels and demographics. These panels show the existing differences in systemic expression of PTX3 by selected demographics. PTX3 levels were higher in females (A) and in patients with early-onset disease (B). ${ }^{*} p<0.05$.

TABLE 2 | Correlations among PTX3 plasma levels and clinical features at univariate analysis.

\begin{tabular}{lcc}
\hline Variable & Spearman's Rho & $\boldsymbol{p}$ \\
\hline Age (years) & $\mathrm{NS}$ & $\mathrm{NS}$ \\
Age at disease onset (years) & $\mathrm{NS}$ & $\mathrm{NS}$ \\
Z-score (activity) & 0.181 & 0.016 \\
Z-score (damage) & $\mathrm{NS}$ & $\mathrm{NS}$ \\
ESR (mm/h) & 0.229 & 0.0002 \\
CRP (mg/l) & 0.128 & 0.035 \\
Prednisone dose (mg) & 0.198 & 0.001 \\
\hline
\end{tabular}

regression included sex, diagnosis, disease activity, history and activity of small-vessel inflammation, history, and activity of large-vessel inflammation, and steroid therapy. The stepwise algorithm resulted in a model including disease activity $(\mathrm{B}=$ 3.162, Std.Err $=0.738, \mathrm{p}<0.001)$ and activity of small vessel inflammation $(B=4.200$, Std.Err $=1.579, p=0.008)$. In a second iteration, disease activity was excluded due to high colinearity with the other variables. The final regression model (Table 4) included activity of small vessel inflammation $(B=6.706$, Std.Err $=1.473, p<0.001)$, activity of large vessel inflammation $(\mathrm{B}=$ 4.269, Std.Err $=0.844, p=0.008)$, and diagnosis $(B=0.243$, Std.Err $=0.121, p=0.046)$.

\section{DISCUSSION}

In this brief report, we present a multi-disease comparison of PTX3 plasma profile in patients with various systemic autoimmune and inflammatory conditions. In line with previous evidence from other groups and us $(20,21,23,24,26,44-$ 46), we observed that PTX3 levels rise in acutely inflamed patients. Accordingly, PTX3 levels are higher in patients with recent onset disease [see also $(23,47)$ ] and correlated with disease activity and with conventional inflammatory markers such as ESR and CRP. However, PTX3 blood levels do not merely reflect systemic inflammation, and indeed they failed to increase in conditions such as RA and PMR. The relative lack of PTX3 increase well-agrees with the role of PTX3 as a tissuegenerated signal: the inflamed synoviae possibly represent the preferential site of PTX3 generation and it has been reported that PTX3 assessment in the synovial fluid might indeed be more informative $(27,48)$.

Clinically overt vascular inflammation involving small or large vessels was associated with elevated PTX3 levels. Identification of reliable biomarkers for vascular inflammation assessment constitutes a significant unmet need in current Rheumatology practice (49-55). The present study supports the contention that vascular inflammation is a major driver of PTX3 elevation $(20,23,56)$.

Patients with SLE had the highest PTX3 levels. PTX3 correlated with active SLE as estimated by the number of highscore BILAG domains. Aberrant presentation of autoantigens due to non-physiological release of PTX3 $(13,28,57)$ could be involved, as indicated by the protective role of anti-PTX3 antibodies in $\operatorname{SLE}(58,59)$. Corticosteroids are major inducers of PTX3 at a systemic level (60) and can constitute an additional modulatory variable in this setting. In particular, systemic administration of corticosteroid drugs or exposure to higher endogenous glucocorticoid levels cause an overall rise in blood PTX3 levels. Nonetheless, glucocorticoids have divergent effects on different cell types as they dampen PTX3 expression in monocyte-derived dendritic cells, but significantly induce PTX3 in endothelial cells and fibroblasts (60). Consistently, corticosteroids also exert distinct biological effects over different pathogenic backgrounds (61). Alternatively, smoldering vascular inflammation might be advocated as a potential explanation for plasma PTX3 elevation in patients with SLE and for conflicting results in the literature regarding associations with clinically overt vasculitis $(26,62-65)$.

Single tissue/organ-limited inflammatory events not involving the vascular bed might not represent effective stimuli for PTX3 elevation in the circulating blood. In line with this view, 
A

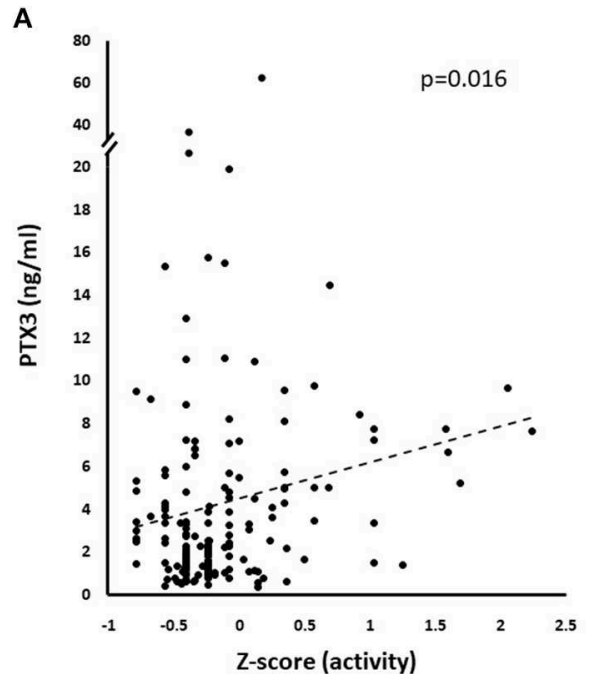

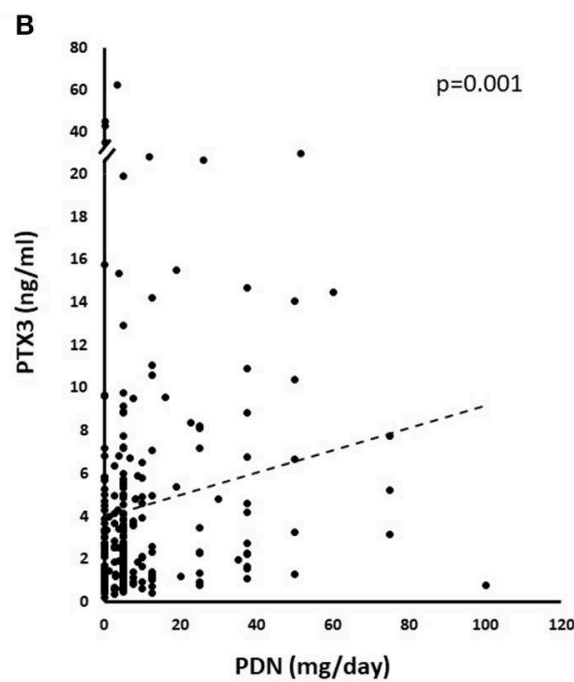

FIGURE 3 | Correlations with PTX3 levels. PTX3 correlated with multiple disease and treatment-related variables at univariate analysis. (A) Depicts the linkage between increasing normalized activity score (Z-activity) and PTX3 plasma levels. (B) Shows the potential influence of corticosteroid treatment on PTX3 circulating levels.

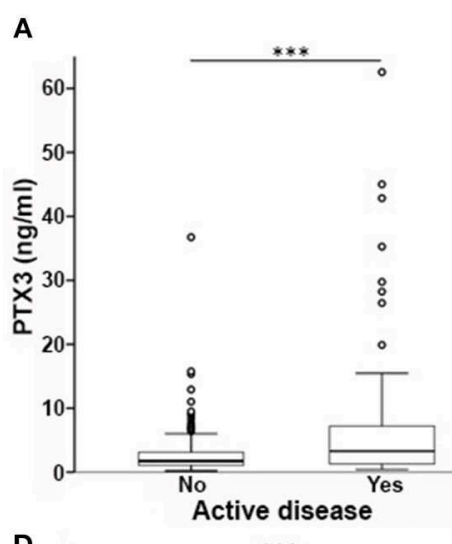

D

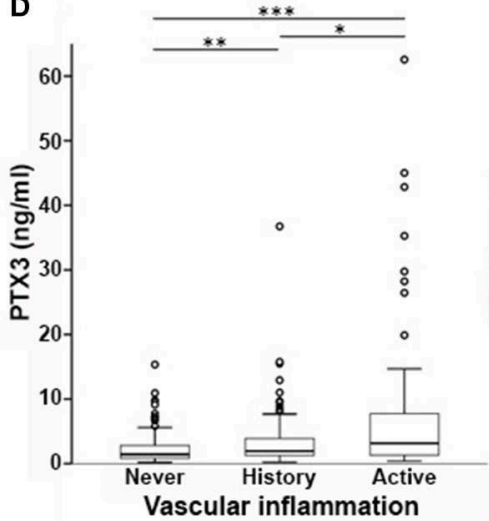

B

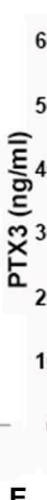

E

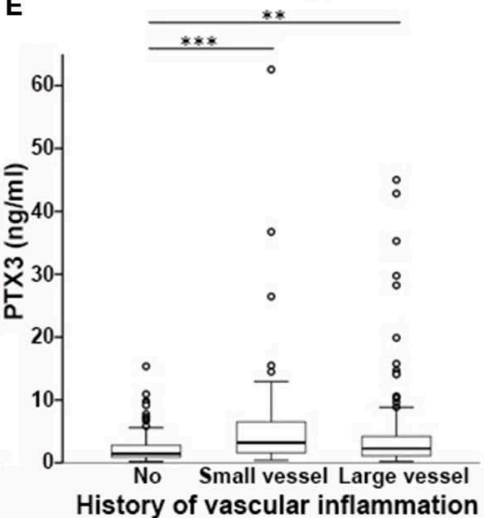

C

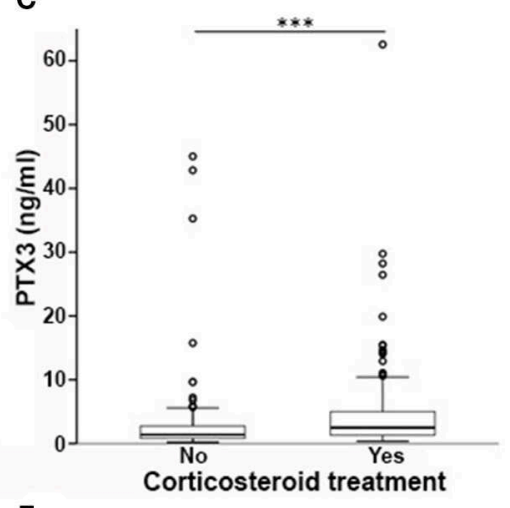

$\mathbf{F}$

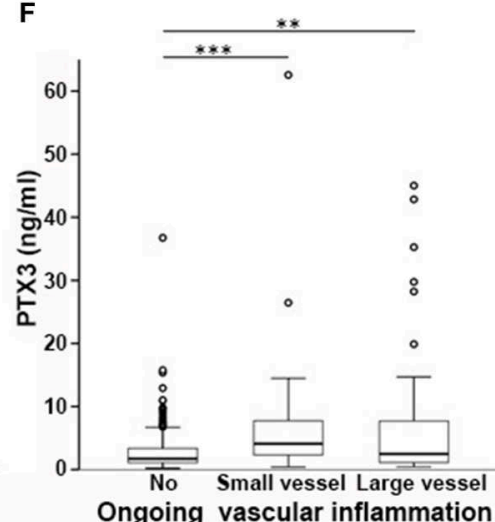

FIGURE 4 | PTX3 levels and disease phenotypes. In this multi-panel graph, differences in PTX3 plasma levels among phenotype groups are highlighted. PTX3 levels were higher in patients with active disease (A), but not with accrued irreversible damage (B). PTX3 was also higher in patients on corticosteroids (C). (D) Depicts the existing differences between patients with vs. without a history of vasculitis and between active or quiescent vasculitis at time of sampling. In (E,F) patients are stratified according to a history (E) or ongoing activity (F) of small- or large-vessel vasculitis associated with higher levels of PTX3 when compared to no vasculitis. ${ }^{\star} p<0.05 ;{ }^{* *} p<0.01 ;{ }^{* \star *} p<0.001$. 
TABLE 3 | Correlations among PTX3 levels and clinical variables in patients with SLE.

\begin{tabular}{lll}
\hline & \multicolumn{2}{c}{ Correlation with PTX3 } \\
\hline & All patients & Patients on PDN \\
\hline Age & No & No \\
Disease duration & No & No \\
SLEDAl-2K & Yes & No \\
PGA & Yes & No \\
Patient's VAS & Yes (inverse) & No \\
Erythrocyte sedimentation rate & No & No \\
CRP levels & No & No \\
C3 levels & No & No \\
C4 levels & Yes (inverse) & No \\
Anti-DNA titres & No & No \\
PDN dose & No & Yes \\
\hline
\end{tabular}

TABLE 4 | Multivariate linear model of PTX3 levels.

\begin{tabular}{lccc}
\hline & B & Std. error & p-value \\
\hline Active small-vessel inflammation & 6.706 & 1.473 & $<0.001$ \\
Active large-vessel inflammation & 4.269 & 0.844 & 0.008 \\
Diagnosis & 0.243 & 0.121 & 0.046 \\
History of small-vessel inflammation & 1.148 & 1.122 & 0.307 \\
History of large-vessel inflammation & 0.607 & 0.862 & 0.482 \\
Sex & -0.354 & 0.750 & 0.637 \\
Steroid therapy & -0.260 & 0.828 & 0.754 \\
\hline
\end{tabular}

$R^{2}$ of the model including the significant variables: 0.122

relatively low PTX3 concentrations were found in plasma from patients with RA, PMR and AAV without vasculitic features in this and other studies $(20,44)$. Neutrophil, endothelial cells and vessel-residing mononuclear cells can all concur to PTX3 release in the circulating blood during acute and chronic vascular injury $(8,11)$. PTX3 might be part of a protective response to the extension and exacerbation of organ damage due to post-ischemic inflammation $(21,29)$. However, PTX3 can also promote vascular injury under septic conditions (66). Furthermore, as a constituent of the antimicrobial array embedded in neutrophil extracellular traps (NETs) (10), PTX3 can concur to NETs-related immunothrombosis $(58,67)$ and similarly to neutrophil myeloperoxidase and proteinase-3 (which are also enclosed in NETs), promote the generation of pathogenic antibodies (68). Anti-PTX3 antibodies have been proposed represent atypical ANCA and, in contrast to SLE, might correlate with disease activity in patients with AAV (69).

This study has limitations. Systemic diseases without primary vessel inflammation are relatively underrepresented, which warrants caution in the interpretation of PTX3 dynamics in these settings. In addition, this study only explored the clinical relevance of PTX3 as a biomarker of vascular inflammation, without any deeper insight into the pathogenic drivers of this phenotype. Further mechanistic studies are thus needed to address this issue and possibly refine our knowledge on potential applications of PTX3 in diagnostics and therapy. To this purpose, dissecting the role of glucocorticoids as confounding factors for PTX3 expression would be of particular relevance, due to the widespread use of corticosteroid drugs in immunemediated diseases.

Taken together, these data suggest that PTX3 could be implicated in multiple distinct pathophysiological events causing and maintaining inflammation in immune-mediated diseases. From a diagnostic point of view, PTX3 elevation in the circulating blood marks the occurrence of inflammatory events in blood vessels and might find a specific niche in clinical practice as a tool to identify vasculitic subsets among patients with autoimmune diseases.

\section{ETHICS STATEMENT}

The study was performed under the Autoimmuno-Mol protocol, approved by the Ethics Committee of the San Raffaele Institute, Milan, Italy; reference number 2/2013/INT.

\section{AUTHOR CONTRIBUTIONS}

AAM, PR-Q, GR, and ET designed the study. MaB, GR, ET, $\mathrm{MiB}, \mathrm{SS}, \mathrm{MD}$, and $\mathrm{RD}$ collected clinical data. RL performed PTX3 evaluation. AM supervised the laboratory analysis and provided critical intellectual contribution to the study design and implementation. GR and ET analyzed clinical and laboratory data. GR, ET, and AAM drafted and revised the manuscript. The final version of the manuscript was approved by all authors.

\section{FUNDING}

This work was supported by grants from the MIUR (2015MGBEM2_002), and the Ministero della Salute (RF_2013_02358715) to AAM as well as the PR-Q and European Research Council (ERC - No 69415), Fondazione Cariplo (Contract no. 2015-0564) and Cluster Alisei (MEDINTECH CTN01_00177_962865) to AM.

\section{ACKNOWLEDGMENTS}

We are grateful to the B.I.R.D. Foundation Europe, Costozza di Longare (VI), Italy for its support to our School of Allergy and Immunology.

\section{SUPPLEMENTARY MATERIAL}

The Supplementary Material for this article can be found online at: https://www.frontiersin.org/articles/10.3389/fimmu. 2019.01135/full\#supplementary-material

Supplementary Figure 1 | PTX3 levels in SLE. Boxplots depicting the existing differences in PTX3 plasma levels among patients with SLE stratified by disease activity, history of vascular inflammation and vasculitic activity. Patients with active disease not comprising any vascular involvement (V.I.) and patients with active vascular involvement in SLE showed a trend toward higher PTX3 levels compared to patients with clinically quiescent disease. 


\section{REFERENCES}

1. Hickey MJ, Kubes P. Intravascular immunity: the host-pathogen encounter in blood vessels. Nat Rev Immunol. (2009) 9:364-75. doi: 10.1038/ nri2532

2. Stark K, Eckart A, Haidari S, Tirniceriu A, Lorenz M, von Bruhl ML, et al. Capillary and arteriolar pericytes attract innate leukocytes exiting through venules and 'instruct' them with pattern-recognition and motility programs. Nat Immunol. (2013) 14:41-51. doi: 10.1038/ni.2477

3. Ramirez GA, Rovere-Querini P, Sabbadini MG, Manfredi AA. Parietal and intravascular innate mechanisms of vascular inflammation. Arth Res Therap. (2015) 17:16. doi: 10.1186/s13075-015-0528-2

4. Gaertner F, Massberg S. Blood coagulation in immunothrombosis-At the frontline of intravascular immunity. Semin Immunol. (2016) 28:561-9. doi: 10.1016/j.smim.2016.10.010

5. Maugeri N, Rovere-Querini P, Manfredi AA. Disruption of a regulatory network consisting of neutrophils and platelets fosters persisting inflammation in rheumatic diseases. Front Immunol. (2016) 7:182. doi: 10.3389/fimmu.2016.00182

6. Semple JW, Italiano JEJr, Freedman J. Platelets and the immune continuum. Nat Rev Immunol. (2011) 11:264-74. doi: 10.1038/nri2956

7. Erreni M, Manfredi AA, Garlanda C, Mantovani A, Rovere-Querini P. The long pentraxin PTX3: A prototypical sensor of tissue injury and a regulator of homeostasis. Immunol Rev. (2017) 280:112-25. doi: 10.1111/imr.12570

8. Garlanda C, Bottazzi B, Magrini E, Inforzato A, Mantovani A. PTX3, a humoral pattern recognition molecule, in innate immunity, tissue repair, and cancer. Physiol Rev. (2018) 98:623-39. doi: 10.1152/physrev.00016.2017

9. Garlanda C, Bottazzi B, Bastone A, Mantovani A. Pentraxins at the crossroads between innate immunity, inflammation, matrix deposition, and female fertility. Annu Rev Immunol. (2005) 23:337-66. doi: 10.1146/annurev.immunol.23.021704.115756

10. Jaillon S, Peri G, Delneste Y, Fremaux I, Doni A, Moalli F, et al. The humoral pattern recognition receptor PTX3 is stored in neutrophil granules and localizes in extracellular traps. J Exp Med. (2007) 204:793-804. doi: 10.1084/jem.20061301

11. Manfredi AA, Rovere-Querini P, Bottazzi B, Garlanda C, Mantovani A. Pentraxins, humoral innate immunity and tissue injury. Curr Opin Immunol. (2008) 20:538-44. doi: 10.1016/j.coi.2008.05.004

12. Salustri A, Garlanda C, Hirsch E, De Acetis M, Maccagno A, Bottazzi $\mathrm{B}$, et al. PTX3 plays a key role in the organization of the cumulus oophorus extracellular matrix and in in vivo fertilization. Development. (2004) 131:1577-86. doi: 10.1242/dev.01056

13. Baruah P, Propato A, Dumitriu IE, Rovere-Querini P, Russo V, Fontana R, et al. The pattern recognition receptor PTX3 is recruited at the synapse between dying and dendritic cells, and edits the cross-presentation of self, viral, and tumor antigens. Blood. (2006) 107:151-8. doi: 10.1182/blood-2005-03-1112.

14. Canti V, Castiglioni MT, Rosa S, Franchini S, Sabbadini MG, Manfredi AA, et al. Pregnancy outcomes in patients with systemic autoimmunity. Autoimmunity. (2012) 45:169-75. doi: 10.3109/08916934.2011.593600

15. Assandri R, Monari M, Colombo A, Dossi A, Montanelli A. Pentraxin 3 plasma levels and disease activity in systemic lupus erythematosus. Autoimmune Dis. (2015) 2015:354014. doi: 10.1155/2015/354014

16. Bonavita E, Gentile S, Rubino M, Maina V, Papait R, Kunderfranco $\mathrm{P}$, et al. PTX3 is an extrinsic oncosuppressor regulating complementdependent inflammation in cancer. Cell. (2015) 160:700-14. doi: 10.1016/j.cell.2015.01.004

17. Grcevic D, Sironi M, Valentino S, Deban L, Cvija H, Inforzato A, et al. The long pentraxin 3 plays a role in bone turnover and repair. Front Immunol. (2018) 9:417. doi: 10.3389/fimmu.2018.00417

18. Presta M, Foglio E, Churruca Schuind A, Ronca R. Long Pentraxin3 modulates the angiogenic activity of fibroblast growth factor-2. Front Immunol. (2018) 9:2327. doi: 10.3389/fimmu.2018.02327

19. Rodrigues PF, Matarazzo S, Maccarinelli F, Foglio E, Giacomini A, Silva Nunes JP, et al. Long pentraxin 3-mediated fibroblast growth factor trapping impairs fibrosarcoma growth. Front Oncol. (2018) 8:472. doi: 10.3389/fonc.2018. 00472

20. Fazzini F, Peri G, Doni A, Dell'Antonio G, Dal Cin E, Bozzolo E, et al. PTX3 in small-vessel vasculitides: an independent indicator of disease activity produced at sites of inflammation. Arthritis Rheum. (2001) 44:28412850.doi: 10.1002/1529-0131(200112)44:12<2841::AID-ART472>3.0.CO;2-6

21. Garlanda C, Bottazzi B, Moalli F, Deban L, Molla F, Latini R, et al. Pentraxins and atherosclerosis: the role of PTX3. Curr Pharm Des. (2011) 17:38-46. doi: 10.2174/138161211795049750

22. Maugeri N, Rovere-Querini P, Slavich M, Coppi G, Doni A, Bottazzi B, et al. Early and transient release of leukocyte pentraxin 3 during acute myocardial infarction. J Immunol. (2011) 187:970-9. doi: 10.4049/jimmunol.1100261

23. Baldini M, Maugeri N, Ramirez GA, Giacomassi C, Castiglioni A, PrietoGonzalez S, et al. Selective up-regulation of the soluble pattern-recognition receptor pentraxin 3 and of vascular endothelial growth factor in giant cell arteritis: relevance for recent optic nerve ischemia. Arthritis Rheum. (2012) 64:854-65. doi: 10.1002/art.33411

24. Tombetti E, Di Chio MC, Sartorelli S, Papa M, Salerno A, Bottazzi B, et al. Systemic pentraxin-3 levels reflect vascular enhancement and progression in Takayasu arteritis. Arthritis Res Ther. (2014) 16:479. doi: 10.1186/s13075-014-0479-Z

25. Shirai Y, Okazaki Y, Inoue Y, Tamura Y, Yasuoka H, Takeuchi T, et al. Elevated levels of pentraxin 3 in systemic sclerosis: associations with vascular manifestations and defective vasculogenesis. Arthritis Rheumatol. (2015) 67:498-507. doi: 10.1002/art.38953

26. Sahin S, Adrovic A, Barut K, Durmus S, Gelisgen R, Uzun H, et al. Pentraxin-3 levels are associated with vasculitis and disease activity in childhood-onset systemic lupus erythematosus. Lupus. (2017) 26:1089-94. doi: $10.1177 / 0961203317699286$

27. Weitoft T, Larsson A, Saxne T, Manivel VA, Lysholm J, Knight A, et al. Pentraxin 3 in serum and synovial fluid of patients with rheumatoid arthritis with and without autoantibodies. Scand J Rheumatol. (2017) 46:346-52. doi: 10.1080/03009742.2016.1244288

28. Rovere P, Peri G, Fazzini F, Bottazzi B, Doni A, Bondanza A, et al. The long pentraxin PTX3 binds to apoptotic cells and regulates their clearance by antigen-presenting dendritic cells. Blood. (2000) 96:4300-6.

29. Deban L, Russo RC, Sironi M, Moalli F, Scanziani M, Zambelli V, et al. Regulation of leukocyte recruitment by the long pentraxin PTX3. Nat Immunol. (2010) 11:328-34. doi: 10.1038/ni.1854

30. Leavitt RY, Fauci AS, Bloch DA, Michel BA, Hunder GG, Arend WP, et al. The American college of rheumatology 1990 criteria for the classification of Wegener's granulomatosis. Arthritis Rheum. (1990) 33:11017. doi: 10.1002/art.1780330807

31. Sharma BK, Jain S, Suri S, Numano F. Diagnostic criteria for Takayasu arteritis. Int $J$ Cardiol. (1996) 54 (Suppl.):S141-7. doi: 10.1016/0167-527302647-2

32. Watts R, Lane S, Hanslik T, Hauser T, Hellmich B, Koldingsnes W, et al. Development and validation of a consensus methodology for the classification of the ANCA-associated vasculitides and polyarteritis nodosa for epidemiological studies. Ann Rheum Dis. (2007) 66:222-7. doi: 10.1136/ard.2006.054593

33. Hochberg MC. Updating the American College of Rheumatology revised criteria for the classification of systemic lupus erythematosus. Arthritis Rheum. (1997) 40:1725. doi: 10.1002/art.1780400928

34. Pineton de Chambrun M, Wechsler B, Geri G, Cacoub P, Saadoun D. New insights into the pathogenesis of Behcet's disease. Autoimmun Rev. (2012) 11:687-98. doi: 10.1016/j.autrev.2011.11.026

35. Aletaha D, Neogi T, Silman AJ, Funovits J, Felson DT, Bingham COIII, et al. 2010 Rheumatoid arthritis classification criteria: an American College of Rheumatology/European League Against Rheumatism collaborative initiative. Arthritis Rheum. (2010) 62:2569-81. doi: 10.1002/art.27584

36. Gladman DD, Ibanez D, Urowitz MB. Systemic lupus erythematosus disease activity index 2000. J Rheumatol. (2002) 29:288-91.

37. Mukhtyar C, Lee R, Brown D, Carruthers D, Dasgupta B, Dubey S, et al. Modification and validation of the Birmingham Vasculitis Activity Score (version 3). Ann Rheum Dis. (2009) 68:1827-32. doi: 10.1136/ard.2008.101279

38. Misra R, Danda D, Rajappa SM, Ghosh A, Gupta R, Mahendranath $\mathrm{KM}$, et al. Development and initial validation of the Indian Takayasu Clinical Activity Score (ITAS2010). Rheumatology. (2013) 52:1795-801. doi: 10.1093/rheumatology/ket128

39. Isenberg DA, Rahman A, Allen E, Farewell V, Akil M, Bruce IN, et al. BILAG 2004. Development and initial validation of an updated version 
of the British Isles Lupus Assessment Group's disease activity index for patients with systemic lupus erythematosus. Rheumatology. (2005) 44:902-6. doi: 10.1093/rheumatology/keh624

40. Gladman DD, Goldsmith CH, Urowitz MB, Bacon P, Fortin P, Ginzler E, et al. The Systemic Lupus International Collaborating Clinics/American College of Rheumatology (SLICC/ACR) Damage Index for Systemic Lupus Erythematosus International Comparison. J Rheumatol. (2000) 27:373-6.

41. Mohammad AJ, Bakoush O, Sturfelt G, Segelmark M. The extent and pattern of organ damage in small vessel vasculitis measured by the Vasculitis Damage Index (VDI). Scand J Rheumatol. (2009) 38:268-75. doi: $10.1080 / 03009740802668554$

42. Sivakumar M. Outcome of vascular interventions in takayasu arteritis using the takayasu arteritis damage score. Arthritis Rheumatism. (2011) 63.

43. Peri G, Introna M, Corradi D, Iacuitti G, Signorini S, Avanzini F, et al. PTX3, A prototypical long pentraxin, is an early indicator of acute myocardial infarction in humans. Circulation. (2000) 102:636-641. doi: 10.1161/01.CIR.102.6.636

44. Pulsatelli L, Peri G, Macchioni P, Boiardi L, Salvarani C, Cantini F, et al. Serum (10): S588. levels of long pentraxin PTX3 in patients with polymyalgia rheumatica. Clin Exp Rheumatol. (2010) 28:756-8.

45. Dagna L, Salvo F, Tiraboschi M, Bozzolo EP, Franchini S, Doglioni C, et al. Pentraxin-3 as a marker of disease activity in Takayasu arteritis. Ann Intern Med. (2011) 155:425-33. doi: 10.7326/0003-4819-155-7-20111004 0-00005

46. Zhang J, Shan L, Koussih L, Redhu NS, Halayko AJ, Chakir J, et al. Pentraxin 3 (PTX3) expression in allergic asthmatic airways: role in airway smooth muscle migration and chemokine production. PLOS ONE. (2012) 7:e34965. doi: 10.1371/journal.pone.0034965

47. Klimek E, Skalska A, Kwasny-Krochin B, Surdacki A, Sulicka J, Korkosz M, et al. Differential associations of inflammatory and endothelial biomarkers with disease activity in rheumatoid arthritis of short duration. Mediators Inflamm. (2014) 2014:681635. doi: 10.1155/2014/681635

48. Luchetti MM, Piccinini G, Mantovani A, Peri G, Matteucci C, Pomponio $\mathrm{G}$, et al. Expression and production of the long pentraxin PTX3 in rheumatoid arthritis (RA). Clin Exp Immunol. (2000) 119:196-202. doi: 10.1046/j.1365-2249.2000.01110.x

49. Monach PA. Biomarkers in vasculitis. Curr Opin Rheumatol. (2014) 26:24-30. doi: 10.1097/BOR.0000000000000009

50. Weyand CM, Goronzy JJ. Clinical practice. Giant-cell arteritis and polymyalgia rheumatica. $N$ Engl J Med. (2014) 371:50-7. doi: 10.1056/NEJMcp1214825

51. Carmona FD, Martín J, González-Gay MA. New insights into the pathogenesis of giant cell arteritis and hopes for the clinic. Expert Rev Clin Immunol. (2016) 12:57-66. doi: 10.1586/1744666X.2016.1089173

52. Tombetti E, Colombo B, Di Chio MC, Sartorelli S, Papa M, Salerno A, et al. Chromogranin-A production and fragmentation in patients with Takayasu arteritis. Arthritis Res Ther. (2016) 18:187. doi: 10.1186/s13075-016-1082-2

53. Tombetti E, Maugeri N, Rovere-Querini P, Manfredi AA. Biomarkers of vascular inflammation. Cell stress offers new clues. Int J Cardiol. (2017) 246:18-9. doi: 10.1016/j.ijcard.2017.05.115

54. Tombetti E, Godi C, Ambrosi A, Doyle F, Jacobs A, Kiprianos AP, et al. Novel angiographic scores for evaluation of large vessel vasculitis. Sci Rep. (2018) 8:15979. doi: 10.1038/s41598-018-34395-7

55. Tombetti E, Mason JC. Takayasu arteritis: recent advances and hopes for the future. Rheumatology. (2019) [epub ahead of print].

56. Baragetti A, Knoflach M, Cuccovillo I, Grigore L, Casula M, Garlaschelli K, et al. Pentraxin 3 (PTX3) plasma levels and carotid intima media thickness progression in the general population. Nutr Metab Cardiovasc Dis. (2014) 24:518-23. doi: 10.1016/j.numecd.2013.10.030

57. Jaillon S, Jeannin P, Hamon Y, Fremaux I, Doni A, Bottazzi B, et al. Endogenous PTX3 translocates at the membrane of late apoptotic human neutrophils and is involved in their engulfment by macrophages. Cell Death Differ. (2009) 16:465-74. doi: 10.1038/cdd.2008.173
58. Bassi N, Ghirardello A, Blank M, Zampieri S, Sarzi-Puttini P, Mantovani A, et al. IgG anti-pentraxin 3 antibodies in systemic lupus erythematosus. Ann Rheum Dis. (2010) 69:1704-10. doi: 10.1136/ ard.2009.117804

59. Gatto M, Ghirardello A, Luisetto R, Bassi N, Fedrigo M, Valente $\mathrm{M}$, et al. Immunization with pentraxin 3 (PTX3) leads to antiPTX3 antibody production and delayed lupus-like nephritis in NZB/NZW F1 mice. J Autoimmun. (2016) 74:208-16. doi: 10.1016/ j.jaut.2016.07.002

60. Doni A, Mantovani G, Porta C, Tuckermann J, Reichardt HM, Kleiman A, et al. Cell-specific regulation of PTX3 by glucocorticoid hormones in hematopoietic and nonhematopoietic cells. J Biol Chem. (2008) 283:29983-92. doi: $10.1074 /$ jbc.M805631200

61. Wu GC, Li J, Leng RX, Li XP, Li XM, Wang DG, et al. Identification of long non-coding RNAs GAS5, linc0597 and lnc-DC in plasma as novel biomarkers for systemic lupus erythematosus. Oncotarget. (2017) 8:23650-63. doi: 10.18632/oncotarget.15569

62. Lech M, Rommele C, Kulkarni OP, Susanti HE, Migliorini A, Garlanda C, et al. Lack of the long pentraxin PTX3 promotes autoimmune lung disease but not glomerulonephritis in murine systemic lupus erythematosus. PLoS ONE. (2011) 6:e20118. doi: 10.1371/ journal.pone.0020118

63. Shimada Y, Asanuma YF, Yokota K, Yoshida Y, Kajiyama H, Sato K, et al. Pentraxin 3 is associated with disease activity but not atherosclerosis in patients with systemic lupus erythematosus. Mod Rheumatol. (2014) 24:78-85. doi: 10.3109/14397595.2013.852837

64. Skare TL, Nisihara R, Ramos GP, Utiyama SR, Messias-Reason I. Pentraxin3 levels in systemic lupus erythematosus: association with cumulative damage but not with disease activity. Joint Bone Spine. (2015) 82:466-7. doi: 10.1016/j.jbspin.2014.09.003

65. Wirestam L, Enocsson H, Skogh T, Eloranta ML, Ronnblom L, Sjowall C, et al. Interferon-alpha coincides with suppressed levels of pentraxin3 (PTX3) in systemic lupus erythematosus and regulates leucocyte PTX3 in vitro. Clin Exp Immunol. (2017) 189:83-91. doi: 10.1111/ cei. 12957

66. Souza DG, Amaral FA, Fagundes CT, Coelho FM, Arantes RM, Sousa LP, et al. The long pentraxin PTX3 is crucial for tissue inflammation after intestinal ischemia and reperfusion in mice. Am J Pathol. (2009) 174:1309-18. doi: 10.2353/ajpath.2009.080240

67. Ramirez GA, Manfredi AA, Rovere-Querini P, Maugeri N. Bet on NETs! Or on how to translate basic science into clinical practice. Front Immunol. (2016) 7:417. doi: $10.3389 /$ fimmu.2016.00417

68. Sangaletti S, Tripodo C, Chiodoni C, Guarnotta C, Cappetti B, Casalini $\mathrm{P}$, et al. Neutrophil extracellular traps mediate transfer of cytoplasmic neutrophil antigens to myeloid dendritic cells toward ANCA induction and associated autoimmunity. Blood. (2012) 120:3007-18. doi: 10.1182/ blood-2012-03-416156

69. Simon A, Subra JF, Guilpain P, Jeannin P, Pignon P, Blanchard S, et al. Detection of anti-pentraxin-3 autoantibodies in ANCA-associated vasculitis. PLoS ONE. (2016) 11:e0147091. doi: 10.1371/journal.pone.0147091

Conflict of Interest Statement: The authors declare that the research was conducted in the absence of any commercial or financial relationships that could be construed as a potential conflict of interest.

Copyright $\odot 2019$ Ramirez, Rovere-Querini, Blasi, Sartorelli, Di Chio, Baldini, De Lorenzo, Bozzolo, Leone, Mantovani, Manfredi and Tombetti. This is an open-access article distributed under the terms of the Creative Commons Attribution License (CC $B Y)$. The use, distribution or reproduction in other forums is permitted, provided the original author(s) and the copyright owner(s) are credited and that the original publication in this journal is cited, in accordance with accepted academic practice. No use, distribution or reproduction is permitted which does not comply with these terms. 